\title{
Estratégias de Governo para Promover o Desenvolvimento de Software Livre
}

\author{
Clairmont Borges ${ }^{1}$, Cláudio F.R. Geyer ${ }^{2}$ \\ ${ }^{1,2}$ Instituto de Informática, Universidade Federal do Rio Grande do Sul, \\ Av. Bento Gonçalves, 9500, Bloco IV, Porto Alegre, RS, Brasil \\ clermont@inf.ufrgs.br geyer@inf.ufrgs.br
}

\begin{abstract}
Resumo - Este artigo apresenta nossa visão sobre estratégias de governo para promover o desenvolvimento de Software Livre. Esta visão é baseada nas nossas atividades de pesquisa e nas experiências práticas em trabalhar com desenvolvimento de Software Livre. Este artigo também descreve suscintamente porque é importante usar Software Livre e como o seu modelo econômico parece funcionar.
\end{abstract}

Palavras-chave: Software Livre, Modelo Econômico, Estratégias de Governo.

\begin{abstract}
This paper presents our vision about government strategies to promote Free Software development. This vision is based on our research activities and practical experiences on working with Free Software development. This paper also briefly describes why it is important to use Free Software and how its economic model seems to work.
\end{abstract}

Key-words: Free Software, Economic Model, Government Strategies.

\section{Introdução}

O software está presente em praticamente todas as atividades e relações humanas. $O$ software, além de ser um conjunto de instruções executáveis automaticamente no computador, é também uma representação de conhecimento - e conhecimento é poder.

Os estados democráticos estão fundamentados na contínua busca do equilíbrio entre os principais poderes. Sendo o software uma nova forma de poder, o Software Livre permite promover o crescimento econômico com justiça social, conforme veremos ao longo deste artigo.

\section{Por Quê Usar Software Livre} destacar:

Dentre as principais razões, podemos

- Maior segurança: acesso ao código fonte permite auditoria. Um indicador da importância da segurança é o sistema operacional GNU/Linux da National Security Agency (NSA) - EUA [1];

- Menor custo: a licença General Public License (GPL) da Free Software Foundation/GNU autoriza cópias ilimitadas [2];
- Maior qualidade: o código aberto é muito mais estudado e testado;

- Maior flexibilidade: acesso ao código fonte - permite adaptações em tempo hábil;

- Mais Vida Útil: os computadores não são descartados com o passar do tempo, mas transferidos/doados para aplicações que usam Software Livre adaptados para aproveitar a capacidade computacional existente. Por exemplo, convertendo-os em terminais clientes de servidores de ambientes gráficos - onde as aplicações são processadas;

- Mais empregos: no setor de serviços, através de treinamento, suporte, consultoria e desenvolvimento;

- Mais pesquisas: nas universidades, indústrias e demais centros, promovendo: (i) O desenvolvimento de novas soluções aplicadas às necessidades regionais. Por exemplo, o software Direto - Agenda, Catálogo e Correio Eletrônico [3, 4]; e (ii) A cooperação internacional para resolver problemas complexos e de interesse comum - desenvolvendo tecnologias estratégicas. O maior exemplo é o sistema operacional GNU/Linux; 
- Maior integração: entre educação, pesquisa, indústria e comércio. Vivemos em sociedade, temos interesses comuns;

- Mais cidadania: O Software Livre estimula a solidariedade e a cooperação, refletindo positivamente na conscientização e participação política. Por exemplo, no Projeto Software Livre - RS [5], diversos segmentos da sociedade gaúcha participam para planejar 0 desenvolvimento do Software Livre. Naturalmente, a escolha de prioridades para o Movimento do Software Livre é um exercício saudável de política;

- Desenvolvimento Auto-Sustentável: através do crescimento econômico com inclusão social.

\section{Modelo Econômico do Software Livre}

Dentro da nossa visão de pesquisadores e da nossa experiência prática com Software Livre [6], podemos destacar estas características fundamentais:

- A reprodução de software em série tem um custo ínfimo (se comparado com demais bens e produtos): basicamente se concentra no custo da mídia de suporte e/ou de distribuição;

- A licença GNU/GPL [2] autoriza reprodução ilimitada;

- O transporte de bits é muito mais barato que o transporte de átomos. Além disso, o contínuo crescimento das redes de computadores (principalmente a Internet) reduz cada vez mais os custos de transportar bits;

- Software Livre é baseado em padrões abertos, e os padrões abertos tendem a crescer mais. Exemplos representativos são a rede Internet e a arquitetura do Personal Computer (PC);

- Custos de desenvolvimento subsidiados: $\begin{array}{llr}\text { uma parcela significativa das } & \text { criação } \\ \text { contribuições de }\end{array}$ aperfeiçoamento de Software Livre é, em grande parte, oriunda de: (i) Trabalho voluntário: inúmeras razões, as quais variam do puro prazer de programar ao mais nobre altruísmo; (ii) Cooperação: ao resolver um problema específico, se a solução é compartilhada na forma de Software Livre com a comunidade da Internet, aumentam as probabilidades de surgirem contribuições complementares, reduzindo custos e evoluindo a solução inicial; (iii) Atividades educacionais: ao mesmo tempo que 0 processo educacional qualifica e forma pessoas, também produz resultados aplicados ao Software Livre - através de exercícios, trabalhos, dissertações e teses; e (iv) Atividades industriais e comerciais: fabricantes e comerciantes desenvolvem as interfaces e camadas de Software Livre que integram seus produtos aos nichos de Software Livre já existentes;

- Venda de Software Livre como serviço: treinamento, suporte, consultoria $\mathrm{e}$ desenvolvimento. Um cenário ilustrativo: Segundo [7], a empresa Red Hat Software atua no negócio de Commodity - onde atuam também, por exemplo, distribuidores de água mineral. Fazendo uma analogia com montadoras de carro, a Red Hat Software atua como uma "montadora de Software Livre", identificando demandas do mercado, reunindo os componentes (as "peças de Software Livre"), integrando, testando, distribuindo e dando suporte para estes componentes. A Red Hat Software identificou como oportunidade de negócio: oferecer conveniência e qualidade, ao mesmo tempo em que estabelece sua marca na mente dos consumidores. A Red Hat Software usa também a estratégia do distribuidor de água, oferecendo o Linux "oficial" da Red Hat Software com a garantia de ser proveniente de uma "boa fonte" - neste caso, uma equipe altamente qualificada e competente naquilo que faz;

- Fatores humanos e geográficos: o Movimento do Software Livre vai fortalecer o setor de serviços em todos os países, porque o fator humano influencia muito - razão porque gostamos e sentimos segurança em conhecer nossos médicos, advogados, enfim - todas as pessoas que são importantes para nós. Uma vez que as relações humanas são fundamentais para conquistar confiança, - fator de distribuição geográfica dos serviços se estabelece naturalmente, devido ao custo de deslocar pessoas;

- O desenvolvimento de novas tecnologias estratégicas em Software Livre será financiado por: (i) Governos (para promover o crescimento econômico com justiça social): Áreas extremamente estratégicas são custeadas pelos governos, a exemplo da agência espacial norte-americana, a NASA; (ii) Empresas Distribuidoras de Software Livre e 
Cooperativas de Software Livre (para garantir a continuidade da venda de seus serviços): Estas empresas e cooperativas vão destinar parte de seus faturamentos para promover o desenvolvimento de Software Livre; (iii) Instituições de Ensino Privadas e Públicas (para garantir a continuidade do domínio sobre 0 conhecimento de software): Estas instituições podem financiar diretamente, destinando recursos específicos. E/ou, financiar indiretamente, orientando as atividades educacionais para gerar contribuições em Software Livre; e (iv) Federações de Indústria e Comércio (para obter software de maior segurança, mais qualidade e menor custo): podem destinar fundos para desenvolver soluções em Software Livre para suas necessidades comuns. Além disso, podem estabelecer parcerias com os demais agentes financiadores e desenvolvedores de Software Livre, para que a sinergia seja obtida mais rapidamente;

Por causa do custo ínfimo de se reproduzir software em série, aliado ao direito legal de poder (ilimitadamente) copiar e distribuir Software Livre, o financiamento do desenvolvimento de Software Livre consegue obter retorno sobre o investimento, com poderoso efeito multiplicador de resultados.

\section{Estratégias de Governo para Promover o Desenvolvimento de Software Livre}

Algumas das considerações feitas aqui são resultantes de um trabalho realizado em grupo, pela Coordenação do Projeto Software Livre - RS no estado do Rio Grande do Sul [8], da qual participamos. A seguir ressaltamos alguns dos itens mais importantes:

- Promover pesquisas e análises sobre o novo modelo econômico baseado no Software Livre, visando potencializá-lo;

- Adotar o uso gradual de Software Livre nos serviços públicos: (i) Preferencialmente: nos casos onde os softwares proprietários ainda concorrem fortemente; e (ii) Obrigatoriamente: nos sistemas e serviços estratégicos, onde a segurança e a autonomia são imprescindíveis; Por exemplo, eleições, imposto de renda, forças armadas e outros;

- Criar programas de apoio à formação de organizações não-governamentais encarregadas de planejar e promover 0 desenvolvimento de Software Livre, de maneira mais imune às eventuais instabilidades políticas;

- Criar uma agência para estabelecer cooperação internacional institucional para o desenvolvimento de tecnologias estratégicas em Software Livre;

- Promover políticas de incentivo à formação de Cooperativas de Software Livre, as quais vão prestar serviços e desenvolver soluções;

- Investir fortemente no uso de Software Livre na área educacional, em todos os níveis, gerando profissionais qualificados em Software Livre, ao mesmo tempo em que produz contribuições ao Software Livre como resultado das atividades educacionais (exercícios, trabalhos, dissertações e teses). Um exemplo representativo é o projeto Rede Escolar Livre-RS [9];

- Criar políticas de incentivos fiscais para financiadores e desenvolvedores de Software Livre.

\section{Conclusões}

Um dos principais objetivos de todo governo é promover o desenvolvimento autosustentável e com justiça social. Portanto, promover o desenvolvimento de Software Livre também é uma obrigação dos governos.

A sociedade, por sua vez, deve estar atenta e organizada para fazer valer sua vontade. O fato do sistema operacional GNU/Linux ser o único concorrente do Windows demonstra a força do Software Livre. Certamente, com a organização e o apoio dos principais agentes econômicos comprometidos com a segurança e o bem-estar social, o Software Livre crescerá mais rapidamente, até ocupar todos os nichos de mercado.

Naturalmente, todo processo evolutivo envolve também dificuldades e obstáculos. O Software Livre certamente encontrará desafios, mas suas vantagens justificam e compensam todos os esforços para desenvolvê-lo.

\section{Agradecimentos}

À comunidade do Projeto Software Livre$\mathrm{RS}$, que propiciou as idéias aqui relatadas.

\section{Referências}

1. National Security Agency - EUA. SecurityEnhanced Linux http://www.nsa.gov/selinux /index.html (acesso em Mar/2003). 
2. Free Software Foundation / GNU. General Public License. http://www.gnu.org/copyleft /gpl.html (acesso em Mar/2003).

3. Mazoni, M. A Experiência de Gestão Pública da Informática no RS. IP - Revista Informática Pública, Edição 1, Ano 2000. Editada pela Empresa de Informática e Informação do Município de Belo Horizonte PRODABEL.

4. PROCERGS / Governo do Estado do Rio Grande do Sul. Direto - Software Aberto de Correio, Agenda e Catálogo. http://www.direto.org.br/ (acesso em Mar/2003).

5. Governo do Estado do Rio Grande do Sul. Projeto Software Livre - RS. http://www.softwarelivre.rs.gov.br/ (acesso em Mar/2003).
6. Projeto DIRETO - Sistemas Avançados para Comunicação Eletrônica - Software Aberto de Correio, Agenda e Catálogo. FAPERGS Edital 06/2000. http://www.inf.ufrgs.br /procpar/direto/ (acesso em Mar/2003).

7. Young, R. Giving It Away - How Red Hat Software Stumbled Across a New Economic Model and Helped Improve an Industry. DiBona, C., Ockman, S., Stone, M. (editors). Open Sources: Voices from the Open Source Revolution, O’Reilly \& Associates, 1999.

8. PROCERGS / Governo do Estado do Rio Grande do Sul. Coordenação do Projeto Software Livre - RS. coordenacao@ server.codigoaberto.org. $\mathrm{Br}$

9. [9] Governo do Rio Grande do Sul. Rede Escolar Livre - RS. http://www .redeescolarlivre.rs.gov.br/ (acesso em Mar/2003). 